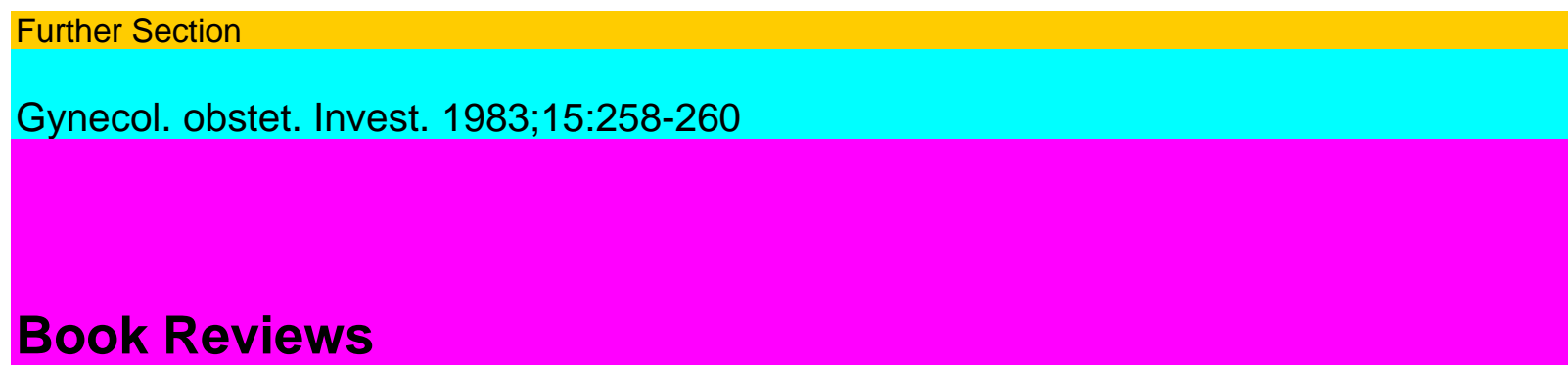

\title{
M. Renaer
}

Chronic Pelvic Pain in Women

Springer, Berlin 1981197 pp., 22 fig., 10 tab. DM 69.-/USS 32.90 ISBN 3-540-10608-1

Female patients not infrequently complain of chronic pain referred to the iliac region on one or other side and sometimes on both sides. This area is often loosely termed the Ovarian region'. The left side is more frequently affected than the right, and in the majority of cases the subjects of pain of this type are women of more or less pronounced nervous disposition. The ovary may be somewhat enlarged and more sensitive than usual on bimanual examination but without restriction of its mobility. In other cases the organs may be abnormally small. If there is evidence of inflammation affecting the Fallopian tube and ovary on the same side as the pain, the latter is naturally attributed to the inflammatory process. It should be recognized, however, that the pain may be associated with the presence of minute foci of pelvic endometriosis in relation to either the ovary or adjacent peritoneum. In many instances no definite abnormality can be detected and such patients are to be regarded with due caution. Care must therefore be exercised and careful examination is mandatory in order to determine as precisely as possible any local conditions which may or may not be present.

Pain arising from disease of the female genital tract is not characteristic either in its distribution or general features. It may be closely simulated by hysterical states. The areas to which the pain is most commonly referred are the hypogastric zone of the abdomen, the spine from the lumbar region to the coccyx and the front and interaspects of the thighs. What is all too frequently forgotten by gynecologists is that small hernial protrusions are often the cause of considerable discomfort, and the femoral and inguinal rings should always be carefully examined, and in cases of doubt it is useful to make the examination with the patient in the erect posture.

Psychosomatic disorders are common in gynecologic practice and the symptomatology may closely simulate organic pelvic disease. It is well known that intense emotion may evoke somatic accompaniments. Such emotion may be but a brief incident, or may be prolonged when the emotional resentment or instability emanates from insecurity. It is appreciated that different emotions will produce different somatic reactions. What is important clinically is that different impulses from the periphery may dominate the patient's consciousness, and may form the leading complaints to the exclusion of any spontaneous reference to the psychological factor that originally evoked them. The latter can be unmasked only by an adequate history, and it is relevant to say that if that history shows no intelligible reason for assuming the existence of a morbid emotional state it is unwise to regard any symptoms that the patient may have as functional even if they are not referable to organic pathology. This is a timely publication on a subject which involves all physicians and should be read by all who are baffled by the chronic pain syndrome.

David Charles, Huntington, W.Va.

Book Reviews

259 


\section{D.A.M. Gebbie Reproductive Anthropology}

Descent through Woman Wiley, New York 1981371 pp.; US\$ 19.50 ISBN 0-471-27985-4

As indicated in this volume there are certain perdurable human truths and values immune to geographic or historical vitiation. The classic view with its Judeo-Christian modifications acknowledges that we are flawed but not therefore ignoble; the classical view is famously realistic about our limitations, but celebrates our sense of possibility in the idea of hope. Indeed, the one ignoble thing from the classical perspective is despair.

The author who hails from Glasgow has written a book which reflects not only his background, but the encounters which have motivated him during his sojourn in various parts of Africa and the Pacific. He has produced a book which covers not only various aspects of fertility and parturition, but a volume depicting his philosophy. The idea behind this book and its implied philosophy are mentally provocative. His philosophy ranges from the radical to the puritanical and it depicts how the author has floundered and then returned to course by reproductive anthropology. No influence has been more powerful than that of anthropology in impressing upon historians the profoundly important truth of the essential unity of the human race.

Two significant results of the revelations of anthropology and archaeology have been the critical revision of the whole Biblical story of the Creation and fall of man, together with an illuminating reconstruction of the records of the early doings of Israel; as well as the complete abandonment of all the older attempts to formulate a philosophy of history. In short, history has ceased to concern itself with a priori speculations as to the purpose for which the world and man were created, and it has aligned itself with the other sciences which are endeavoring to explain to the human mind the meaning of things as they are.

Many aspects of cultural anthropology have been addressed in this volume and it makes interesting reading despite some typographical errors. It will bring forth a reaction from many of its readers as it reflects the author's avant-garde and puritanical thought processes. There is no doubt that like David Livingstone, the author has accomplished much since he left his native land.

David Charles, Hunington, W. Va.

P. Felig, J.D. Baxter, A.E. Broadus, L·A. Frohman Endocrinology and Metabolism McGraw-Hill, New York 19811388 pp., DM229.10 ISBN 0-07-020387-3

This is a well-organized and highly readable textbook. Periodically in the evolution of an important branch of clinical medicine there develops a medical need for a text which combines the clinical aspects of disease syndromes with an in-depth review of the applicable basic science aspects.

\section{Book Reviews}

260

It is a tremendous accomplishment on the part of the editors to collect so many eminent authorities who have addressed the various endocrine and metabolic disorders. Considering there are numerous contributors, the literary style is of a high order and the volume will fill an important place in medical libraries and provide experts and students in the field of endocrinology an authoritative source for reference.

The volume is divided into eight parts and the first part dealing with general endocrinology should be read by all who have to deal with the problems that are encountered in health and disease involving the endocrine glands. The fifth part deals with gonadal disease and it should be read by all subspecialists in infertility. The treatment of ovulatory disorders remains one of the most rewarding areas of infertility and, as pointed out by the contributor, both patients and 
physicians appear to have misconceptions concerning therapy. There is no evidence to suggest that any of the ovulation-inducing agents produce superfertility and should be used with the understanding that they can only approximate normal fertility. Therefore, there is no justification for the use of any ovulation-inducing agent in a patient who does not have an established ovulatory disorder. Likewise, the various aspects of amenorrhea are admirably portrayed and the chapter includes a fine description of the use of bromocriptine for the treatment of amenorrhea and galactor-rhea.

The volume also includes a sound review of the physiology of prolactin in addition to the evaluation of hyperprolactinemia and a discussion of the management of the various syndromes associated with this entity.

All in all, again I wish to congratulate the editors on a highly successful first edition and one will see this go on and become a standard textbook available to all medical students and subspecialists who require further information pertaining to this ever expanding segment of clinical medicine.

David Charles, Huntington, W.Va. 